\title{
Nem centro, nem periferia: o cinema de bordas
}

\section{Barbara Heller}

\section{Resenha}

SANTANA, Gelson (org.). Cinema de bordas 2.

São Paulo: Ed. a lápis, 2008.

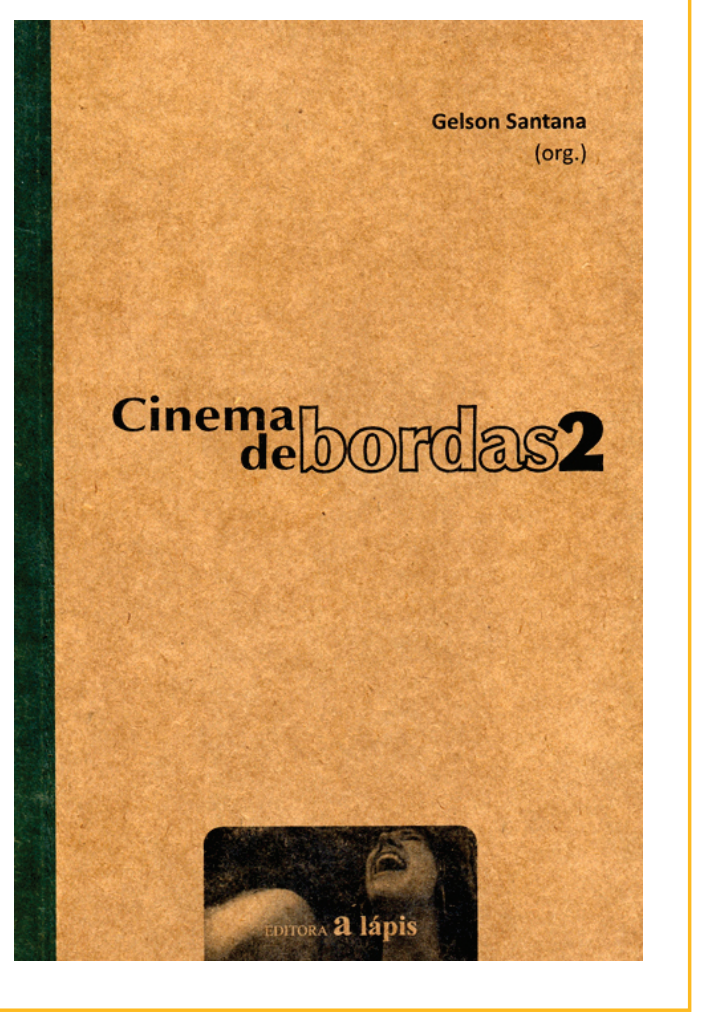

\section{Barbara Heller | b.heller@terra.com.br}

Doutora em Teoria Literária pela Universidade Estadual de Campinas - UNICAMP -, e mestre em Comunicação pela Universidade de São Paulo - USP. Docente no mestrado em Comunicação da Universidade Paulista - UNIP.
Uma mala cheia de dinheiro vivo é trocada, por acaso, por outra idêntica, e, no lugar das pilhas organizadas de cédulas, encontram-se torneiras, ferramentas e pedaços de canos, para desespero do protagonista.

Um jovem do interior do Rio Grande do Sul consegue, finalmente, a oportunidade de passar a noite com a moça mais bonita da cidade, mas inúmeros e improváveis acontecimentos adiam esse tão esperado encontro, que se consumará quando o dia estiver quase raiando.

Rambú (qualquer semelhança fonética com Rambo não é mera coincidência) age no Amazonas, mas, não fosse a interferência do pajé, sequer se conscientizaria de sua condição de herói.

Pessoas morando nos subterrâneos, onde recuperam clorofila e oxigênio, são impedidas de voltar à superfície, que se tornou letal.

Estas e muitas outras histórias são analisadas no livro Cinema de bordas 2. Organizado por Gelson Santana e publicado em 2008 pela Editora a lápis, a obra dá continuidade aos trabalhos, iniciados em 2006, de um grupo de pesquisadores 
preocupados em investigar e compreender a produção de determinados realizadores de cinema que, com uma câmera VHS na mão e uma (ou mais) ideia(s) na cabeça, produzem não um, mas vários filmes.

Bombeiros, pedreiros, camelôs, faxineiros, estudantes de comunicação, atores e jornalistas são algumas das profissões deste grupo de realizadores que filmam motivados pela paixão pelo cinema. Nenhum deles, como se vê, sobrevive do cinema que produzem. Orçamentos baixíssimos, falas regionais, atores amadores, locações em cemitérios, praças e ruas das cidades onde moram elenco e equipe, ênfase no humor e/ou no terror, dificuldades de exibição e, mais ainda, de distribuição são algumas das características comuns desse tipo de cinema.

Porém, diferentemente do cinema de periferia, com os quais pode ser confundido, o cinema de bordas não se opõe ao cinema dominante, nem se propõe a ser paródia. Ele oferece entretenimento descompromissado, mas, quando precisa, se apropria, sem constrangimento, de exemplos extraídos do cinema tradicional e também da televisão.

É Marcius Freire (apud SANTANA, 2008, p. 13), na introdução do livro, quem primeiro se encarrega de explicar no que 0 cinema de bordas se diferencia dos outros filmes não-profissionais e, ao mesmo tempo, quem aproxima este tipo de cinema à arte naïf, a partir do conceito criado pelo pintor Jean Dubuffet: "produções de qualquer espécie [...] que apresentam um caráter espontâneo e fortemente inventivo [...] tendo por autores pessoas obscuras, estrangeiras aos meios artísticos profissionais".

Nos textos que seguem, os dez pesquisadores, apresentados por ordem alfabética, analisam em seus artigos a sinopse dos filmes, a biografia de seus realizadores, as condições em que foram produzidos e exibidos e não economizam esforço para contextualizar, tanto no corpo do texto, como em numerosas e generosas notas de rodapé, os conceitos que dão sustentação às suas análises.

Um deles - e talvez o mais elástico e complexo de todos - é o conceito de gênero - mais especificamente, de gênero cinematográfico. Rosana Soares (apud SANTANA, 2008, p. 184) lembra que "em geral, os gêneros visam não apenas estabelecer relações entre produção, produto e audiência, mas, sobretudo, determinar categorias e modos de agrupar, por similitude, os diferentes filmes". 0 que há em comum, nesta grande diversidade de filmes, segundo a pesquisadora, são as marcas autorais de seus realizadores e das comunidades onde estão inseridos, além de elementos da atual cultura midiática.

Paracinema, outro conceito que explica e justifica o cinema de bordas, é apresentado por Laura Cánepa, a partir da formulação de Jeffrey Sconce (apud SANTANA, 2008, p. 96):

[...] uma forma de leitura de determinadas produções audiovisuais que valoriza todo 0 tipo de 
'lixo' rejeitado ou ignorado pela cultura dita 'legítima', não se tratando propriamente de um grupo distinto de filmes, muito menos a um gênero específico. Trata-se de uma estratégia de leitura que procura 0 sublime no ruim, no desviante $\mathrm{e}$ não na familiaridade, dando atenção a uma estética da aberração e da variação estilística.

Além desses, muitos outros conceitos também são apresentados ao leitor. Porém, é possível afirmar que, entre os pesquisadores desta coletânea, todos são consensuais sobre a importância do receptor nesse tipo de filme, e por isso destaco, no espaço que já começa a escassear, a presença do conceito de mediações, de Jesús Martín-Barbero, no texto de Bernadette Lyra (apud SANTANA, 2008, p. 44): "processo produtor de significações e não de mera circulação de informações, na qual, 0 receptor, portanto, não é um simples codificador daquilo que o emissor depositou na mensagem, mas também um produtor".

A maior qualidade do Cinema de bordas 2, entretanto, não está exatamente na diversidade dos conceitos apresentados, nem apenas no interesse que as sinopses despertam, nem nas análises competentes de todos os autores, mas, isto sim, na abertura que este grupo de pesquisa demonstra ao levar a sério, num lugar tão sério como a academia, filmes de realizadores das mais diversas regiões do Brasil que muitas vezes nos fazem gargalhar gostosamente. 


\section{Expediente}

A revista E-Compós é a publicação científica em formato eletrônico da Associação Nacional dos Programas de Pós-Graduação em Comunicação (Compós). Lançada em 2004, tem como principal finalidade difundir a produção acadêmica de pesquisadores da área de Comunicação, inseridos em instituições do Brasil e do exterior.
E-COMPÓS I www.e-compos.org.br I E-ISSN 1808-2599

Revista da Associação Nacional dos Programas de Pós-Graduação em Comunicação. Brasília, v.12, n.1, jan./abr. 2009.

A identificação das edições, a partir de 2008 passa a ser volume anual com três números.

\section{CONSELHO EDITORIAL}

\section{Afonso Albuquerque}

Universidade Federal Fluminense, Brasil

Alberto Carlos Augusto Klein

Universidade Estadual de Londrina, Brasi

Alex Fernando Teixeira Primo

Universidade Federal do Rio Grande do Sul, Brasil

\section{Alfredo Vizeu}

Universidade Federal de Pernambuco, Brasil

Ana Carolina Damboriarena Escosteguy

Pontifícia Universidade Católica do Rio Grande do Sul, Bras

Ana Silvia Lopes Davi Médola

Universidade Estadual Paulista, Brasil

André Luiz Martins Lemos

Universidade Federal da Bahia, Brasil

Ângela Freire Prysthon

Universidade Federal de Pernambuco, Brasil

Antônio Fausto Neto

Universidade do Vale do Rio dos Sinos, Brasil

Antonio Carlos Hohlfeldt

Pontifícia Universidade Católica do Rio Grande do Sul, Brasil

Arlindo Ribeiro Machado

Universidade de São Paulo, Brasil

César Geraldo Guimarães

Universidade Federal de Minas Gerais, Brasil

Cristiane Freitas Gutfreind

Pontifícia Universidade Católica do Rio Grande do Sul, Brasil

Denilson Lopes

Universidade Federal do Rio de Janeiro, Brasil

Eduardo Peñuela Cañizal

Universidade Paulista, Brasi

Erick Felinto de Oliveira

Universidade do Estado do Rio de Janeiro, Brasil

Francisco Menezes Martins

Universidade Tuiuti do Paraná, Brasil

Gelson Santana

Universidade Anhembi/Morumbi, Brasi

Hector Ospina

Universidad de Manizales, Colômbia

leda Tucherman

Universidade Federal do Rio de Janeiro, Brasil

Itania Maria Mota Gomes

Universidade Federal da Bahia, Brasil

Janice Caiafa

Universidade Federal do Rio de Janeiro, Brasil

Jeder Silveira Janotti Junior

Universidade Federal da Bahia, Brasil
João Freire Filho

Universidade Federal do Rio de Janeiro, Brasil

John DH Downing

University of Texas at Austin, Estados Unidos

José Luiz Aidar Prado

Pontifícia Universidade Católica de São Paulo, Brasil

José Luiz Warren Jardim Gomes Braga

Universidade do Vale do Rio dos Sinos, Brasil

Juremir Machado da Silva

Pontifícia Universidade Católica do Rio Grande do Sul, Brasil

Lorraine Leu

University of Bristol, Grã-Bretanha

Luiz Claudio Martino

Universidade de Brasília, Brasil

Maria Immacolata Vassallo de Lopes

Universidade de São Paulo, Brasil

Maria Lucia Santaella

Pontifícia Universidade Católica de São Paulo, Brasil

Mauro Pereira Porto

Tulane University, Estados Unidos

Muniz Sodre de Araujo Cabral

Universidade Federal do Rio de Janeiro, Brasil

Nilda Aparecida Jacks

Universidade Federal do Rio Grande do Sul, Brasil

Paulo Roberto Gibaldi Vaz

Universidade Federal do Rio de Janeiro, Brasil

Renato Cordeiro Gomes

Pontifícia Universidade Católica do Rio de Janeiro, Brasil

Ronaldo George Hela

Universidade do Estado do Rio de Janeiro, Brasil

Rosana de Lima Soares

Universidade de São Paulo, Brasil

Rossana Reguillo

Instituto Tecnológico y de Estudios Superiores do Occidente, México

Rousiley Celi Moreira Maia

Universidade Federal de Minas Gerais, Brasil

Sebastião Carlos de Morais Squirra

Universidade Metodista de São Paulo, Brasi

Simone Maria Andrade Pereira de Sá

Universidade Federal Fluminense, Brasil

Suzete Venturelli

Universidade de Brasília, Brasil

Valério Cruz Brittos

Universidade do Vale do Rio dos Sinos, Brasil

Veneza Mayora Ronsini

Universidade Federal de Santa Maria, Brasil

Vera Regina Veiga França

Universidade Federal de Minas Gerais, Brasil
COMISSÃO EDITORIAL

Ana Gruszynski I Universidade Federal do Rio Grande do Sul, Brasil

Rose Melo Rocha I Escola Superior de Propaganda e Marketing, Brasil

CONSULTORES AD HOC

Alberto Schneider I Visitante Tokyo University

Alexandre Rocha da Silva I Universidade Federal do Rio Grande do Sul, Brasil

Fernanda Bruno I Universidade Federal do Rio de Janeiro, Brasil

Ida Stumpf I Universidade Federal do Rio Grande do Sul, Brasil

Kati Caetano I Universidade Tuiuti do Paraná, Brasil

Laura Cánepa I Universidade Anhembi Morumbi, Brasi

Malena Contrera I Universidade Paulista, Brasil

Sandra Gonçalves I Universidade Federal do Rio Grande do Sul, Brasil

Vicente Gosciola I Universidade Anhembi Morumbi, Brasil

REVISÃO DE TEXTO E TRADUÇÃo I Everton Cardoso

EDITORAÇ̃̃o ELETRÔNICA I Raquel Castedo
COMPós I www.compos.org.br

Associação Nacional dos Programas de Pós-Graduação em Comunicação

Presidente

Erick Felinto de Oliveira

Universidade do Estado do Rio de Janeiro, Brasil erickfelinto@uol.com.br

Vice-presidente

Ana Silvia Lopes Davi Médola

Universidade Estadual Paulista, Brasil

asilvia@faac.unesp.br

Secretária-Geral

Denize Correa Araújo

Universidade Tuiuti do Paraná, Brasil

denizearaujo@hotmail.com 